\title{
CLINICAL DISEASES OF RUMINANTS RECORDED AT THE PATUAKHALI SCIENCE AND TECHNOLOGY UNIVERSITY VETERINARY CLINIC
}

\author{
M. A. Rahman ${ }^{* 1}$, M. A. Islam ${ }^{1}$, M. A. Rahman ${ }^{1}$, A. K. Talukder ${ }^{1}$, M. S. Parvin ${ }^{2}$ and M. T. Islam ${ }^{2}$ \\ ${ }^{1}$ Department of Medicine and Surgery, Patuakhali Science and Technology University, Patuakhali, ${ }^{2}$ Department \\ of Medicine, Faculty of Veterinary Science, Bangladesh Agricultural University, Mymensingh
}

\begin{abstract}
This study was conducted at the Patuakhali Science and Technology University Veterinary Clinic, Babugonj, Barisal during the period from January 2008 to December 2011 to report the four years clinical diseases of ruminants. A total of 1241 clinical cases (793 cattle and 448 goats) were recorded and analyzed. Diagnosis of each of the clinical cases was made on clinical history, clinical signs, and faecal examination for parasitic cases. The clinical cases were primarily categorized into three major groups, namely, (1) Medicinal, (2) Gynaeco-obstetrical and (3) Surgical cases. Medicinal cases constituted highest percentage (cattle $84.1 \%$ and goats $81.0 \%$ ) in comparison to gynaeco-obstetrical (cattle $4.7 \%$ and goats $1.1 \%$ ) and surgical (cattle $11.2 \%$ and goats $17.9 \%$ ) cases. Among the medicinal cases in cattle, highest percentage of cases was recorded with parasitic diseases $(50.4 \%)$, followed by general systemic states $(14.8 \%)$ and digestive disorders $(14.2 \%)$. Other cases were respiratory disorders $(5.5 \%)$, infectious diseases $(4.6 \%)$, skin conditions $(3.4 \%)$, eye disease $(3.1 \%)$, urogenital disorders $(1.5 \%)$, metabolic diseases $(1.3 \%)$ and musculo-skeletal disorders $(0.9 \%)$. In case of goats, the highest cases was recorded with digestive disorders $(22.9 \%)$, followed by parasitic diseases $(20.4 \%)$ and respiratory disorders $(16.8 \%)$. Other Medicinal cases in goats were eye diseases $(13.5 \%)$, infectious diseases $(11.8 \%)$, general systemic states $(9.6 \%)$, musculo-skeletal disorder $(3.3 \%)$, skin diseases $(0.8 \%)$ and nutritional deficiency diseases $(0.8 \%)$. Among the gynaeco-obstetrical cases, anestrus $(59.5 \%)$ in cattle and metritis $(40.0 \%)$ in goats were recognized as the major gynaeco-obstetric problems. Traumatic wounds (cattle $-52.8 \%$, goat $-28.8 \%$ ) and castration $(31.3 \%$ ) in goats were recognized as the main disorders which required surgical interventions. It may be concluded that a number of diseases with various percentages have been occurring in the Babugonj upazila and this report will help to prioritize any control measures against major disease conditions reported in this study. However, it is required to estimate the prevalence of diseases in the population of that upazila to have more comprehensive information on the diseases of cattle and goat.
\end{abstract}

Key words: Clinical diseases, cattle, goat

\section{INTRODUCTION}

Livestock constitute an important part of the wealth of a country and it provides leather, and manure, meat and milk to the vast majority of the people. It plays a crucial role in the traditional economy of Bangladesh. Most of these animals under rural conditions in Bangladesh are maintained in traditional management system. Ruminants, especially cattle and goats constitute the major portion of the livestock. About $6.5 \%$ of national GDP is covered by the livestock sector, and its annual rate of productivity is $9 \%$. About $20 \%$ of the populations of Bangladesh earn their livelihood through work associated with raising livestock. South Bengal regions of Bangladesh are low landed and flood/natural calamity affected area which encourages many diseases in livestock. Although some reports on clinical case records from Bangladesh Agricultural University Veterinary Clinic (Rahman et al., 1972; Hossain et al., 1986; Das and Hashim, 1996; Samad, 2001; Samad et al., 2002), Haluaghat Upazila Veterinary Hospital, Mymensingh (Sarker et al., 1999) and Dairy Cooperatives in Pabna district (Pharo, 1987), Trishal Upazila Veterinary Hospital, Mymensingh (Chowdhury et al., 2003), Ulipur Upazila Veterinary Hospital, Kurigram (Kabir et al., 2010) and Chandanaish Upazila of Chittagong district, Bangladesh (Pallab et al., 2012) are available but similar report on ruminant are very limited in South Bengal regions of Bangladesh. This paper reports the four years' clinical diseases of ruminants recorded at the Patuakhali Science and Technology University Veterinary Clinic, Babugonj, Barisal.

*Corresponding e-mail address: anisbgvc@yahoo.com 


\section{A. Rahman and others}

\section{MATERIALS AND METHODS}

This study was carried out on 1241 clinically sick ruminants (cattle $=793$, goat $=448)$ of different ages which were brought for treatment at the Patuakhali Science and Technology University Veterinary Clinic, Babugonj, Barisal over the period from January 2008 to December 2011. The animals were suspected to be affected with different diseases. The presumptive diagnosis of diseases was done on the basis of owner's complaint, clinical history, clinical signs and findings of fecal sample examination for parasitic cases. The clinical cases were primarily categorized into three major groups, such as (1) Medicinal cases (2) Gynaeco-obstetrical cases and (3) Surgical cases. The medicinal cases were categorized into major diagnostic groups that were considered sufficiently distinct so as to make clinical diagnosis accurate, such as (i) systemic states (ii) digestive disorders (iii) respiratory disorders (iv) eye diseases (v) musculo-skeletal disorders (vi) skin conditions (vii) parasitic diseases (viii) infectious diseases (ix) metabolic diseases (x) urogenital disorders and (xi) nutritional defficiency diseases. The study period was divided into three seasons on the basis of local climatic conditions viz. Summer (March to June), Rainy (July to October) and Winter (November to February). Data were organized in the Microsoft ${ }^{\circledR}$ Excel spreadsheet and percentages of disease conditions prevalent in different groups and seasons were calculated. The Chi-square goodness of fit test was done for significant differences in disease conditions among groups and seasons.

\section{RESULTS AND DISCUSSION}

Of the 793 recorded clinical cases of sick cattle, $84.1 \%$ was medicinal, $4.7 \%$ gynaeco-obstetrical and $11.2 \%$ surgical cases (Table 1). Of the 448 clinically sick goats, $81.0 \%$ had medicinal, $1.1 \%$ gynaeco-obstetrical and $17.9 \%$ surgical problems (Table 3). This observation supports the earlier report of Samad (2001) who recorded 90.76\% medicinal, 5.46\% gynaeco-obstetrical and 3.78\% surgical cases in cattle; $76.91 \%$ medicinal, $3.67 \%$ gynaeco-obstetrical and $19.42 \%$ surgical cases in goat during 1999 to 2001 from the Bangladesh Agricultural University (BAU) Veterinary Clinic, Mymensingh. Of the 667 medicinal cases in cattle categorized into ten different groups, the highest cases was recorded with parasitic diseases $(50.4 \%)$, followed by systemic states $(14.8 \%)$ and digestive disorders $(14.2 \%)$. Respiratory disorders were $5.5 \%$ while infectious diseases, skin conditions and eye diseases were $4.6 \%, 3.4 \%$ and $3.1 \%$, respectively. The least recorded cases were musculoskeletal disorder $(0.9 \%)$, metabolic diseases $(1.3 \%)$ and urogenital disorders $(1.5 \%)$ (Table 1). In terms of digestive disorders and skin conditions, this observation is not consistent with the earlier report of Samad et al. (2002) who reported $60.55 \%$ digestive disorders and $14.92 \%$ skin conditions. It is well known that the occurrence of disease varies with different geographical locations. However, other diseases and conditions recorded by Samad et al. (2002) were almost similar in the occurrence with the present study. In case of goats, a total 363 medicinal cases diagnosed in nine different groups, of which highest cases was digestive disorders (22.9\%), followed by parasitic diseases (20.4\%), respiratory disorders $(16.8 \%)$ and eye diseases $(13.5 \%)$ (Table 3). Infectious diseases and systemic states accounted for $11.8 \%$ and $9.6 \%$ cases, respectively. The least recorded cases were with skin diseases $(0.8 \%)$, nutritional deficiency diseases $(0.8 \%)$ and musculo-skeletal disorders (3.3\%).

\section{Medicinal cases}

\section{General systemic states}

Fever and malnutrition in cattle and goats, ill-thrift in cattle and food poisoning in goats were diagnosed under the general systemic states (Tables 1 and 3 ). It was revealed that $5.1 \%$ cattle and $4.4 \%$ goats were affected with fever of unknown etiology. The percentages of occurrence of fever in this study are comparatively lower than the earlier reports of $9.04 \%$ to $12.1 \%$ cases of fever in cattle (Pharo, 1987; Hoque and Samad, 1996; Samad, 2001; Samad et al., 2002) and 10.37\% fever cases in goats (Hoque and Samad, 1997). Although the fever cases was recorded in all the three seasons of the year but highest rate was recorded during rainy both in cattle (6.7\%) and goats (6.3\%). This observation supports the findings of Hoque and Samad (1996) and Samad et al. (2002) who reported higher percentage of fever in calves during rainy and summer seasons. In this study, $8.2 \%$ cases in cattle and $4.9 \%$ cases in goats with malnutrition were recorded. It has been reported earlier in Bangladesh that 3.14\% calves suffer from malnutrition (Samad, 2008). 
Table 1. Year-wise distribution of clinical cases of cattle recorded at the PSTU Veterinary Clinic during four years' period from 2008 to 2011

\begin{tabular}{|c|c|c|c|c|c|c|c|}
\hline \multirow[t]{2}{*}{ SI No. } & \multirow[t]{2}{*}{ Diseases (Cattle) } & \multicolumn{4}{|c|}{ No. (\%) of cases } & \multirow[t]{2}{*}{ Overall } & \multirow[t]{2}{*}{ P-value } \\
\hline & & 2008 & 2009 & 2010 & 2011 & & \\
\hline 1. & Systemic states & $47(20.6)$ & $10(7.1)$ & $18(11.3)$ & $24(17.3)$ & $99(14.8)$ & $<0.001$ \\
\hline i. & Fever & $12(5.3)$ & $5(3.5)$ & $10(6.3)$ & $7(5.0)$ & $34(5.1)$ & \\
\hline ii. & Malnutrition & $25(10.9)$ & $5(3.5)$ & $8(5.0)$ & $17(12.2)$ & $55(8.2)$ & \\
\hline iii. & Ill thrift & $10(4.4)$ & 0 & 0 & 0 & $10(1.5)$ & \\
\hline 2. & Digestive disorders & 33 (14.5) & $11(7.8)$ & 27 (16.9) & $24(17.3)$ & $95(14.2)$ & 0.012 \\
\hline i. & Bloat & $4(1.8)$ & $3(2.1)$ & $2(1.3)$ & $6(4.3)$ & $15(2.2)$ & \\
\hline ii. & Enteritis & $14(6.1)$ & $1(0.7)$ & $8(5.0)$ & $1(0.7)$ & $24(3.6)$ & \\
\hline iii. & Non-specific diarrhea & $14(6.1)$ & $6(4.3)$ & $16(10.1)$ & $15(10.8)$ & $51(7.6)$ & \\
\hline iv. & Stomatitis & $1(0.4)$ & $1(0.7)$ & $1(0.6)$ & $2(1.4)$ & $5(0.8)$ & \\
\hline 3. & Respiratory disorders & $14(6.1)$ & $10(7.1)$ & $8(5.0)$ & $5(3.6)$ & $37(5.5)$ & 0.202 \\
\hline i. & Epistaxis & $1(0.4)$ & $2(1.4)$ & 0 & 0 & $3(0.4)$ & \\
\hline ii. & Pneumonia & $13(5.7)$ & $8(5.7)$ & $8(5.0)$ & $5(3.6)$ & $34(5.1)$ & \\
\hline 4. & Eye diseases & $7(3.1)$ & $8(5.7)$ & $5(3.1)$ & $1(0.7)$ & $21(3.1)$ & 0.140 \\
\hline i. & Conjunctivitis & $4(1.8)$ & $5(3.5)$ & $4(2.5)$ & $1(0.7)$ & $14(2.1)$ & \\
\hline ii. & Corneal opacity & $3(1.3)$ & $3(2.1)$ & $1(0.6)$ & 0 & $7(1.0)$ & \\
\hline 5. & Musculo-skeletal disorder & $3(1.3)$ & 0 & $1(0.6)$ & $2(1.4)$ & $6(0.9)$ & 0.607 \\
\hline i. & Arthritis & $3(1.3)$ & 0 & $1(0.6)$ & $2(1.4)$ & $6(0.9)$ & \\
\hline 6. & Skin conditions & $10(4.4)$ & $6(4.3)$ & $2(1.3)$ & $5(3.6)$ & $23(3.4)$ & 0.127 \\
\hline i. & Dermatitis & $9(3.9)$ & $6(4.3)$ & $1(0.6)$ & $4(2.9)$ & $20(2.9)$ & \\
\hline ii. & Mange & $1(0.4)$ & 0 & $1(0.6)$ & $1(0.7)$ & $3(0.4)$ & \\
\hline 7. & Parasitic diseases & $102(44.7)$ & $78(55.3)$ & $91(57.2)$ & $65(46.8)$ & $336(50.4)$ & 0.027 \\
\hline i. & Helminth infection & $83(36.4)$ & $35(24.8)$ & $52(32.7)$ & $45(32.4)$ & $215(32.2)$ & \\
\hline ii. & Ectoparasitic infestation & $8(3.5)$ & $37(26.2)$ & $34(21.4)$ & $20(14.4)$ & $99(14.8)$ & \\
\hline iii. & Babesiosis & $3(1.3)$ & $2(1.4)$ & 0 & 0 & $5(0.7)$ & \\
\hline iv. & Coccidiosis & $6(2.6)$ & $4(2.8)$ & $5(3.1)$ & 0 & $15(2.2)$ & \\
\hline $\mathrm{v}$. & Stephanofilariasis & $2(0.9)$ & 0 & 0 & 0 & $2(0.3)$ & \\
\hline 8. & Infectious diseases & $7(3.1)$ & $13(9.2)$ & $5(3.1)$ & $6(4.3)$ & $31(4.6)$ & 0.172 \\
\hline i. & Foot-and-mouth disease & $1(0.4)$ & $2(1.4)$ & $1(0.6)$ & $5(3.6)$ & $9(1.3)$ & \\
\hline ii. & Haemorrhagic septicemia & $3(1.3)$ & $1(0.7)$ & 0 & $1(0.7)$ & $5(0.7)$ & \\
\hline iii. & Actinobacillosis & 0 & $1(0.7)$ & $1(0.6)$ & 0 & $2(0.3)$ & \\
\hline iv. & Papillomatosis & $1(0.4)$ & 0 & 0 & 0 & $1(0.1)$ & \\
\hline v. & Foot rot & 0 & $5(3.5)$ & $3(1.9)$ & 0 & $8(1.2)$ & \\
\hline vi. & Rabies & $2(0.9)$ & $4(2.8)$ & 0 & 0 & $6(0.9)$ & \\
\hline 9. & Metabolic diseases & $2(0.9)$ & $4(2.8)$ & $1(0.6)$ & 2 (1.4) & $9(1.3)$ & 0.550 \\
\hline i. & Mastitis & $1(0.4)$ & $3(2.1)$ & 0 & $2(1.4)$ & $6(0.9)$ & \\
\hline ii. & Milk fever & $1(0.4)$ & $1(0.7)$ & $1(0.6)$ & 0 & $3(0.4)$ & \\
\hline 10. & Urogenital disorders & $3(1.3)$ & $1(0.7)$ & $1(0.6)$ & $5(3.6)$ & $10(1.5)$ & 0.221 \\
\hline i. & Semen out & 0 & 0 & 0 & $4(2.9)$ & $4(0.6)$ & \\
\hline ii. & Posthitis & $2(0.9)$ & $1(0.7)$ & $1(0.6)$ & $1(0.7)$ & $5(0.7)$ & \\
\hline iii. & Balanoposthitis & $1(0.4)$ & 0 & 0 & 0 & $1(0.1)$ & \\
\hline & Sub-total (Medicinal cases) & $228(86.7)$ & $141(82.9)$ & $159(83.2)$ & $139(82.2)$ & $667(84.1)$ & $<0.001$ \\
\hline 1. & Repeat breeding & 0 & $1(14.3)$ & $3(50.0)$ & $2(25.0)$ & $6(16.2)$ & \\
\hline 2. & Anestrus & $13(81.3)$ & $2(28.6)$ & $2(33.3)$ & $5(62.5)$ & $22(59.5)$ & \\
\hline 3. & Retained placenta & 0 & $1(14.3)$ & $1(16.7)$ & $1(12.5)$ & $3(8.1)$ & \\
\hline 4. & Metritis & $2(12.5)$ & $1(14.3)$ & 0 & 0 & $3(8.1)$ & \\
\hline 5. & Uterine prolapsed & 0 & $2(28.6)$ & 0 & 0 & $2(2.7)$ & \\
\hline 6. & Dystocia & $1(6.3)$ & 0 & 0 & 0 & $1(1.1)$ & \\
\hline Sub- & total (Gynaeco-obstetrical cases) & $16(6.1)$ & $7(4.1)$ & $6(3.1)$ & $8(4.7)$ & $37(4.7)$ & 0.079 \\
\hline 1. & Abscess & $1(5.3)$ & 0 & 0 & 0 & $1(1.1)$ & \\
\hline 2. & Traumatic wound & $13(68.4)$ & $14(63.6)$ & $9(34.6)$ & $11(50.0)$ & $47(52.8)$ & \\
\hline 3. & Castration & 0 & $1(4.5)$ & $1(3.8)$ & 0 & $2(2.2)$ & \\
\hline 4. & Myiasis & 0 & $4(18.2)$ & $12(46.2)$ & $6(27.3)$ & $22(24.7)$ & \\
\hline 5. & Nasal polyps & 0 & 0 & 0 & $1(4.5)$ & $1(1.1)$ & \\
\hline 6. & Urolithiasis & $1(5.3)$ & 0 & 0 & 0 & $1(1.1)$ & \\
\hline 7. & Dehorning & $2(10.5)$ & $1(4.5)$ & 0 & $1(4.5)$ & $4(4.5)$ & \\
\hline 8. & Navel-ill & $1(5.3)$ & $1(4.5)$ & $4(15.4)$ & $3(13.6)$ & $9(10.1)$ & \\
\hline 9. & Upward patellar fixation & $1(5.3)$ & $1(4.5)$ & 0 & 0 & $2(2.2)$ & \\
\hline & Sub-total (Surgical cases) & $19(7.2)$ & 22 (12.9) & $26(13.6)$ & $22(13.0)$ & $89(11.2)$ & 0.774 \\
\hline & Overall & 263 & 170 & 191 & 169 & 793 & $<0.001$ \\
\hline
\end{tabular}




\section{A. Rahman and others}

\section{Digestive disorders}

Digestive disorders $(22.9 \%)$ were found to be highest among the different categories of diseases in goats. Under this category, diarrhoea was found to be the highest both in cattle and goats, followed by enteritis, bloat, stomatitis, simple indigestion and abdominal pain (Table 1 and 3). However, diarrhoea and enteritis were found to be the major digestive disorders in ruminants. Diarrhoea cases were $7.6 \%$ in cattle and $12.1 \%$ in goats (Table 1 and 3). These observations could be compared well with the $6.94 \%$ of non-specific diarrhoea in dairy cows, $8.99 \%$ in cow-calves and $12.23 \%$ in goats (Hoque and Samad, 1996, 1997). Samad (2001) reported $25.97 \%$ and $9.91 \%$ of diarrhoeal diseases in cattle and goats, respectively. Rahman et al. (1999) reported $4.78 \%$ of diarrhoeal diseases in cattle. Although the diarrhoeal and enteritis cases were recorded in cattle in all the seasons of the year but highest percentage was recorded during rainy $(8.4 \%)$, followed by winter $(7.5 \%)$ and rainy $(7.3 \%)$ (Table 2 ). But in case of goats, highest percentage of diarrhoeal cases was recorded during winter (16.8\%) followed by summer $(9.4 \%)$ and rainy $(10.9 \%)$ seasons and highest percentage of enteritis was recorded during summer $(8.6 \%)$, followed by winter $(6.5 \%)$ and rainy $(3.1 \%)$ seasons (Table 4$)$. This observations contradict with the report of Samad et al. (2002) who reported that diarrhoeal diseases was highest during rainy, followed by summer and lowest during winter seasons.

\section{Respiratory disorders}

Around $5.1 \%$ and $16.8 \%$ cases of pneumonia were recorded in cattle and goats, respectively, and $0.4 \%$ cases of epistaxis were recorded in cattle (Table 1 and 3). Cases of pneumonia in cattle were comparatively higher than the earlier reports of Samad (2001) and Samad et al. (2002) who reported $0.84 \%$ and $1.24 \%$ pneumonia in cattle, respectively. Samad (2001) reported $0.05 \%$ epistaxis in cattle. The cases of pneumonia in goats recorded in this study was about two times higher than the reports of Samad (2001) and Hoque and Samad (1997) who recorded $8.50 \%$ and $8.77 \%$ cases of pneumonia in goats, respectively. The highest percentage of pneumonia was recorded during summer, followed by winter and rainy seasons both in cattle and goats (Table 2 and 4). This observation contradicts with the report of Samad et al. (2002) who reported the highest percentage of pneumonia in cattle during winter $(47.06 \%)$ in comparison to rainy and summer seasons.

\section{Eye diseases}

Conjunctivitis and corneal opacity in cattle and goats were recorded under this group (Table 1 and 3). Comparatively higher percentage of eye diseases was recorded in goats $(13.5 \%)$ than cattle $(3.1 \%)$. This observation supports the earlier report of Samad (2001) who reported the percentage of eye diseases was higher in goats $(7.72 \%)$ than cattle (1.18\%). Debnath et al. (1990) and Samad et al. (2002) reported 1.02\% and 2.42\% eye diseases in calves, respectively. The percentage of eye diseases was highest during summer $(4.2 \%)$ and rainy (3.9\%) seasons than winter $(0.9 \%)$ in case of cattle. This observation is in agreement with the report of Samad et al. (2002) who reported highest percentage of eye diseases during rainy season. Similarly, in case of goats, percentage of eye diseases was highest during rainy $(21.9 \%)$ followed by summer $(9.4 \%)$ and winter $(8.4 \%)$ seasons (Table 4).

\section{Musculo-skeletal disorders}

Arthritis was recorded in only six cattle $(0.9 \%)$ and 12 goats $(3.3 \%)$ (Table 1 and 3 ), which is in agreement with the findings of Samad (2001) who reported $0.02 \%$ and $0.31 \%$ cases of arthritis in cattle and goats, respectively. Both in cattle and goats, the highest percentage of arthritis was reported during summer, followed by winter and rainy seasons (Table 3 and 4 ).

\section{Skin conditions}

Dermatitis was recorded as the major skin disease of cattle and goats, followed by bee sting and mange. About $2.9 \%$ cattle and $0.6 \%$ goats were recorded as dermatitis cases (Table 1 and 3). Samad et al. (2002) also reported dermatitis $(9.64 \%)$ as the major skin disease of calves. In goats, the percentage of dermatitis was $0.66 \%$ as reported by Samad (2001) and Rahman et al. (1999). The highest percentage of dermatitis was recorded in cattle during summer $(4.9 \%)$ than winter $(1.4 \%)$ and rainy $(2.2 \%)$ seasons (Table 4$)$. In goats, the percentage of dermatitis cases was $0.8 \%$ both in summer and rainy seasons (Table 4 ). There was no case of dermatitis during winter season in goats. Samad et al. (2002) reported the higher percentage of dermatitis in calves during summer season $(47.24 \%)$. 


\section{Parasitic diseases}

Parasitic diseases (50.4\%) were found to be highest among the different major diagnostic groups in cattle. Under this group, helminth infection was found to be highest both in cattle and goats, followed by ectoparasitic infestation (Table 1 and 3). Pallab et al. (2012) reported 26.79\% parasitic diseases to all clinical cases, of which $10.13 \%$ in cows, $5.22 \%$ in bulls and $11.43 \%$ in calves. Almost similar percentages of parasitic diseases were recorded during winter $(53.7 \%)$, rainy $(52.2 \%)$ and summer (46.9\%) seasons in cattle (Table 2). In case of goats, the percentages of parasitic diseases were $23.4 \%, 21.9 \%$ and $16.4 \%$ during winter, rainy and summer seasons, respectively (Table 4). Shahadat et al. (2003) reported that the percentage of nematode infection in goats was higher during rainy and winter seasons compared to summer season.

\section{Infectious diseases}

Overall $4.6 \%$ cattle and $11.8 \%$ goats were affected with major infectious diseases (Table 1 and 3), which support the earlier reports of Debnath et al. (1990) and Samad et al. (2002) who reported 5.86\% and 4.73\% specific infectious diseases in calves, respectively. The major infectious diseases in cattle were foot-and-mouth disease $(1.3 \%)$, haemorrhagic septicemia $(0.7 \%)$, actinobacillosis $(0.3 \%)$, papillomatosis $(0.1 \%)$, foot rot $(1.2 \%)$ and rabies $(0.9 \%)$ (Table 1). This observation supports the earlier report of Samad et al. (2002) who reported FMD $(0.56 \%)$, actinomycosis $(0.05 \%)$, papillomatosis $(0.19 \%)$, rabies $(1.09 \%)$ in calves. Debnath et al. (1990) reported $0.88 \%$ FMD and $0.83 \%$ rabies in calves from different upazila veterinary hospitals of Bangladesh. In case of goats, the major infectious diseases were tetanus $(1.1 \%)$, PPR (5.2\%), foot rot (1.4\%) and rabies $(4.1 \%)$ (Table 3). Samad (2001) reported $0.31 \%$ tetanus and $4.29 \%$ rabies in goats. The highest percentage of FMD and foot rot in cattle was recorded during summer, followed by winter and rainy seasons. The percentage of haemorrhagic septicemia in cattle was higher during winter than summer and rainy seasons (Table 2). In goats, the highest percentage of PPR was recorded during summer (8.9\%), followed by winter $(4.7 \%)$ and rainy $(2.3 \%)$ seasons (Table 4).

\section{Metabolic diseases}

Milk fever (0.4\%) and mastitis (0.9\%) was diagnosed in cattle under this group (Table 1$)$. The findings support the report of Sarker et al. (1999) and Samad (2001) who reported clinical mastitis in $0.89 \%$ and $0.71 \%$ cows, respectively. Nooruddin et al. (1986) and Rahman et al. (1999) also reported $0.37 \%$ and $0.65 \%$ clinical mastitis in cows. Comparatively, the higher cases of clinical mastitis was recorded during summer $(1.4 \%)$ than winter $(0.5 \%)$ and rainy seasons $(0.6 \%)$ (Table 2$)$, which contradict with the finding of Samad (2001) who reported higher cases of clinical mastitis during summer (38.67\%) and rainy (38.67\%) seasons than winter $(22.66 \%)$.

\section{Urogenital disorders}

Semen out $(0.6 \%)$, posthitis $(0.7 \%)$ and balanoposthitis $(0.1 \%)$ were recorded in cattle. Samad (2001) recorded $0.31 \%$ of balanoposthitis in young bulls. However, Hossain et al. (1986) and Nooruddin et al. (1986) recorded $3.9 \%$ and $1.44 \%$ cases of posthitis in cattle, respectively. Posthitis was recorded in all the seasons of the year (Table 2). Samad (2001) reported higher percentage of posthitis during rainy $(42.42 \%)$, followed by summer $(30.30 \%)$ and winter $(27.28 \%)$ seasons.

\section{Nutritional deficiency disease}

Vitamin B1 deficiency was reported in $0.8 \%$ goats (Table 3 ) and this observation could not be compared due to lack of similar inland reports.

\section{Gynaeco-obstetrical cases}

\section{Repeat breeding}

This disorder was recorded in 16.2\% cattle and 20.0\% goats (Table 1 and 3). The findings support the observations of Rahman et al. (1975) and Hossain et al. (1986) who reported $22.0 \%$ and $63.0 \%$ of repeat breeding cases in cattle, respectively. However, Rahman et al. (1999) reported lower percentage (0.64\%) of repeat breeding in cattle, and Samad (2001) reported $1.26 \%$ in cattle and $0.24 \%$ in goats. The highest number of repeat breeding in cattle was during winter $(20.0 \%)$, followed by summer $(15.8 \%)$ and rainy $(12.5 \%)$ seasons (Table 2). 


\section{A. Rahman and others}

Table 2. Season-wise distribution of clinical cases of cattle recorded at the PSTU Veterinary Clinic during four years' period from 2008 to 2011

\begin{tabular}{|c|c|c|c|c|c|c|}
\hline \multirow[t]{2}{*}{$\begin{array}{l}\text { SI } \\
\text { No. }\end{array}$} & \multirow[t]{2}{*}{ Diseases (Cattle) } & \multicolumn{4}{|c|}{ No. $(\%)$ of cases } & \multirow[t]{2}{*}{ P-value } \\
\hline & & Winter & Summer & Rainy & Overall & \\
\hline 1. & Systemic states & $36(17.9)$ & $32(11.1)$ & $31(17.4)$ & $99(14.8)$ & 0.809 \\
\hline i. & Fever & $8(3.9)$ & $14(4.9)$ & $12(6.7)$ & $34(5.1)$ & \\
\hline ii. & Malnutrition & $20(9.9)$ & $16(5.6)$ & $19(10.7)$ & $55(8.2)$ & \\
\hline iii. & Ill thrift & $8(3.9)$ & $2(0.7)$ & 0 & $10(1.5)$ & \\
\hline 2. & Digestive disorders & $27(13.4)$ & $42(14.6)$ & $26(14.6)$ & $95(14.2)$ & 0.079 \\
\hline i. & Bloat & $4(1.9)$ & $4(1.4)$ & $7(3.9)$ & $15(2.2)$ & \\
\hline ii. & Enteritis & $7(3.5)$ & $15(5.2)$ & $2(1.1)$ & $24(3.6)$ & \\
\hline iii. & Non-specific diarrhea & $15(7.5)$ & $21(7.3)$ & $15(8.4)$ & $51(7.6)$ & \\
\hline iv. & Stomatitis & $1(0.5)$ & $2(0.7)$ & $2(1.1)$ & $5(0.8)$ & \\
\hline 3. & Respiratory disorders & $11(5.5)$ & $18(6.3)$ & $8(4.5)$ & $37(5.5)$ & 0.118 \\
\hline i. & Epistaxis & $2(0.9)$ & 0 & $1(0.6)$ & $3(0.4)$ & \\
\hline ii. & Pneumonia & $9(4.5)$ & $18(6.3)$ & $7(3.9)$ & $34(5.1)$ & \\
\hline 4. & Eye diseases & $2(0.9)$ & $12(4.2)$ & 7 (3.9) & $21(3.1)$ & 0.028 \\
\hline i. & Conjunctivitis & 0 & $8(2.8)$ & $6(3.4)$ & $14(2.1)$ & \\
\hline ii. & Corneal opacity & $2(0.9)$ & $4(1.4)$ & $1(0.6)$ & $7(1.0)$ & \\
\hline 5. & Musculo-skeletal disorder & $2(0.9)$ & $3(1.0)$ & $1(0.6)$ & $6(0.9)$ & 0.607 \\
\hline i. & Arthritis & $2(0.9)$ & $3(1.0)$ & $1(0.6)$ & $6(0.9)$ & \\
\hline 6. & Skin conditions & $3(1.4)$ & $16(5.6)$ & $4(2.2)$ & $23(3.4)$ & 0.001 \\
\hline i. & Dermatitis & $2(0.9)$ & $14(4.9)$ & $4(2.2)$ & $20(2.9)$ & \\
\hline ii. & Mange & $1(0.5)$ & $2(0.7)$ & 0 & $3(0.4)$ & \\
\hline 7. & Parasitic diseases & $108(53.7)$ & $135(46.9)$ & $93(52.2)$ & $336(50.4)$ & 0.018 \\
\hline i. & Helminth infection & $67(33.3)$ & $77(26.7)$ & $71(39.9)$ & $215(32.2)$ & \\
\hline ii. & Ectoparasitic infestation & $36(17.9)$ & $44(15.3)$ & $19(10.7)$ & $99(14.8)$ & \\
\hline iii. & Babesiosis & $1(0.5)$ & $4(1.4)$ & 0 & $5(0.7)$ & \\
\hline iv. & Coccidiosis & $3(1.5)$ & $10(3.5)$ & $2(1.1)$ & $15(2.2)$ & \\
\hline v. & Stephanofilariasis & $1(0.5)$ & 0 & $1(0.6)$ & $2(0.3)$ & \\
\hline 8. & Infectious diseases & $7(3.5)$ & $18(6.3)$ & $6(3.4)$ & $31(4.6)$ & 0.264 \\
\hline i. & Foot-and-mouth disease & $2(0.9)$ & $6(2.1)$ & $1(0.6)$ & $9(1.3)$ & \\
\hline ii. & Haemorrhagic septicemia & $3(1.5)$ & $1(0.3)$ & $1(0.6)$ & $5(0.7)$ & \\
\hline iii. & Actinobacillosis & 0 & $1(0.3)$ & $1(0.6)$ & $2(0.3)$ & \\
\hline iv. & Papillomatosis & 0 & $1(0.3)$ & 0 & $1(0.1)$ & \\
\hline v. & Foot rot & $1(0.5)$ & $6(2.1)$ & $1(0.6)$ & $8(1.2)$ & \\
\hline vi. & Rabies & $1(0.5)$ & $3(1.0)$ & $2(1.1)$ & $6(0.9)$ & \\
\hline 9. & Metabolic diseases & $3(1.5)$ & $5(1.7)$ & $1(0.6)$ & $9(1.3)$ & 0.045 \\
\hline i. & Mastitis & $1(0.5)$ & $4(1.4)$ & $1(0.6)$ & $6(0.9)$ & \\
\hline ii. & Milk fever & $2(0.9)$ & $1(0.3)$ & 0 & $3(0.4)$ & \\
\hline 10. & Urogenital disorders & $2(0.9)$ & $7(2.4)$ & $1(0.6)$ & $10(1.5)$ & \\
\hline i. & Semen out & 0 & $4(1.4)$ & 0 & $4(0.6)$ & \\
\hline ii. & Posthitis & $2(0.9)$ & $2(0.7)$ & $1(0.6)$ & $5(0.7)$ & \\
\hline iii. & Balanoposthitis & 0 & $1(0.3)$ & 0 & $1(0.1)$ & \\
\hline \multicolumn{2}{|c|}{ Sub-total (medicinal cases) } & $201(89.7)$ & $288(78.0)$ & $178(89.0)$ & $667(84.1)$ & $<0.001$ \\
\hline 1. & Repeat breeding & $2(20.0)$ & $3(15.8)$ & $1(12.5)$ & $6(16.2)$ & \\
\hline 2. & Anestrus & $8(80.0)$ & $8(42.1)$ & $6(75.0)$ & $22(59.5)$ & \\
\hline 3. & Retained placenta & 0 & $2(10.5)$ & $1(12.5)$ & $3(8.1)$ & \\
\hline 4. & Metritis & 0 & $3(15.8)$ & 0 & $3(8.1)$ & \\
\hline 5. & Uterine prolapse & 0 & $2(10.5)$ & 0 & $2(2.7)$ & \\
\hline 6. & Dystocia & 0 & $1(5.3)$ & 0 & $1(1.1)$ & \\
\hline \multicolumn{2}{|c|}{ Sub-total (Gynaeco-obstetrical cases) } & $10(4.5)$ & $19(5.1)$ & $8(4.0)$ & $37(4.7)$ & 0.062 \\
\hline 1. & Abscess & 0 & $1(1.6)$ & 0 & $1(1.1)$ & \\
\hline 2. & Traumatic wound & $7(53.8)$ & $27(43.5)$ & $13(92.9)$ & $47(52.8)$ & \\
\hline 3. & Castration & $1(7.7)$ & $1(1.6)$ & 0 & $2(2.2)$ & \\
\hline 4. & Myiasis & $1(7.7)$ & $21(33.9)$ & 0 & $22(24.7)$ & \\
\hline 5. & Nasal polyps & 0 & $1(1.6)$ & 0 & $1(1.1)$ & \\
\hline 6. & Urolithiasis & $1(7.7)$ & 0 & 0 & $1(1.1)$ & \\
\hline 7. & Dehorning & $1(7.7)$ & $2(3.2)$ & $1(7.1)$ & $4(4.5)$ & \\
\hline 8. & Navel-ill & $2(15.4)$ & $7(11.3)$ & 0 & $9(10.1)$ & \\
\hline 9. & Upward patellar fixation & 0 & $2(3.2)$ & 0 & $2(2.2)$ & \\
\hline \multicolumn{2}{|c|}{ Sub-total (Surgical cases) } & $13(5.8)$ & $62(16.8)$ & $14(7.0)$ & $89(11.2)$ & $<0.001$ \\
\hline \multicolumn{2}{|c|}{ Overall } & 224 & 369 & 200 & 793 & $<0.001$ \\
\hline
\end{tabular}


Diseases of ruminants recorded at PSTU Vet. clinic

\section{Anestrus}

This disorder was recorded in 59.5\% cattle (Table 1). No case was recorded in goats during this study period (Table 3). However, Rahman et al. (1999) reported the reduced number of anestrus cases $(0.83 \%)$ in cattle, and Samad (2001) reported $0.86 \%$ in cattle and $0.47 \%$ in goats. The highest number of cases in cattle was recorded during winter $(80.0 \%)$, followed by rainy $(75.0 \%)$ and summer $(42.1 \%)$ seasons (Table 2$)$.

\section{Retained placenta}

This disorder was recorded only in $8.1 \%$ cows (Table 1) and no case was recorded in does (Table 3). The finding is in conformity with the report of Hossain et al. (1986) who reported $9.1 \%$ cases of retained placenta in cows but contradicts with the reports of Rahman et al. (1999) and Samad (2001) who reported 0.37\% and 0.50\% cases of retained placenta in cows, respectively. The cases of retained placenta were $10.5 \%$ and $12.5 \%$ in summer and rainy seasons, respectively (Table 2).

\section{Metritis}

Metritis was recorded in $8.1 \%$ cows and $40.0 \%$ does (Table 1 and 3). Ali et al. (1997) reported 21.3\% metritis complex from a dairy farm and Islam et al. (1998) reported 5.66\% metritis in cows at different government AI centres from Bangladesh. However, Samad (2001) reported very low percentage of metritis $(0.10 \%)$ in cows. Metritis in cattle was recorded only in summer season (15.8\%) (Table 2).

\section{Uterine prolapse}

Uterine prolapse was recorded in $2.7 \%$ cows and $20.0 \%$ in does (Table 1 and 3). Islam et al. (1998) reported $1.89 \%$ uterine prolapse in cows. In does, Samad (2001) reported $0.08 \%$ cases of uterine prolapse from Bangladesh. In this study, the cases of uterine prolapse were recorded only in summer season both in cows and does (Table 2 and 4).

\section{Dystocia}

Dystocia was recorded only in one cow (1.1\%) and one doe (20.0\%) (Table 1 and 3). Samad (2001) reported $0.02 \%$ and $1.56 \%$ dystocia cases in cows and does, respectively. The dystocia case was recorded only in summer season both in cows and does (Table 2 and 4).

\section{Surgical cases}

Abscess

Abscess was recorded in 1.1\% cattle and 1.3\% goats (Table 1 and 3). This observation supports the reports of Hossain et al. (1986) who recorded 1.2\% cases of abscess in cattle, and of Samad (2001) who reported $1.56 \%$ abscess cases in goats. Abscess was recorded only in summer season both in cattle and goats (Table 2 and 4).

\section{Traumatic wound}

Traumatic wound was found in $52.8 \%$ cattle and $28.8 \%$ goats (Table 1 and 3 ). Hossain et al. (1986) reported $45.2 \%$ traumatic injury in cattle. However, Samad (2001) reported $0.77 \%$ and $2.73 \%$ traumatic wounds in cattle and goats, respectively.

\section{Castration}

Castration was recorded in $2.2 \%$ bull calves and 31.3\% male kids (Table 1 and 3). Hossain et al. (1986) recorded $1.9 \%$ castration cases in bull calves while Samad (2001) recorded $0.02 \%$ and $2.03 \%$ castration cases in bull calves and male kids, respectively.

\section{Myiasis}

Myiasis was recorded in $24.7 \%$ cattle and $16.4 \%$ goats (Table 1 and 3 ). The highest number of myiasis cases was observed during summer (cattle $33.9 \%$ and goats $22.0 \%$ ) in comparison to winter (cattle $7.7 \%$ and goats $7.1 \%$ ) seasons while no case was recorded in rainy season both in cattle and goats (Table 2 and 4). Samad (2001) also recorded the highest myiasis cases in cattle and goats during summer season in comparison to winter season. 


\section{A. Rahman and others}

Table 3. Year-wise distribution of clinical cases of goats recorded at the PSTU Veterinary Clinic during four years' period from 2008 to 2011

\begin{tabular}{|c|c|c|c|c|c|c|c|}
\hline \multirow[t]{2}{*}{ SI No. } & \multirow[t]{2}{*}{ Diseases (Goat) } & \multicolumn{4}{|c|}{ No. (\%) of cases } & \multirow[t]{2}{*}{ Overall } & \multirow[t]{2}{*}{ P-value } \\
\hline & & 2008 & 2009 & 2010 & 2011 & & \\
\hline 1. & Systemic states & $9(7.1)$ & $8(8.9)$ & $10(13.2)$ & 8 (11.4) & $35(9.6)$ & 0.957 \\
\hline i. & Fever & $4(3.1)$ & $2(2.2)$ & $4(5.3)$ & $6(8.6)$ & $16(4.4)$ & \\
\hline ii. & Malnutrition & $5(3.9)$ & $5(5.6)$ & $6(7.9)$ & $2(2.9)$ & $18(4.9)$ & \\
\hline iii. & Food poisoning & 0 & $1(1.1)$ & 0 & 0 & $1(0.3)$ & \\
\hline 2. & Digestive disorders & $32(25.2)$ & $14(15.6)$ & $21(27.6)$ & $16(22.9)$ & $83(22.9)$ & 0.025 \\
\hline i. & Bloat & $2(1.6)$ & $2(2.2)$ & $3(3.9)$ & $2(2.9)$ & $9(2.5)$ & \\
\hline ii. & Simple Indigestion & $1(0.8)$ & 0 & $1(1.3)$ & $1(1.4)$ & $3(0.8)$ & \\
\hline iii. & Enteritis & $18(14.2)$ & $4(4.4)$ & 0 & 0 & $22(6.1)$ & \\
\hline iv. & Diarrhoea & $9(6.9)$ & $7(7.8)$ & $17(22.4)$ & $11(15.7)$ & $44(12.1)$ & \\
\hline $\mathrm{v}$. & Abdominal pain & 0 & 0 & 0 & $2(2.9)$ & $2(0.6)$ & \\
\hline vi. & Stomatitis & $2(1.6)$ & $1(1.1)$ & 0 & 0 & $3(0.8)$ & \\
\hline 3. & Respiratory disorder & $32(25.2)$ & $11(12.2)$ & $10(13.2)$ & $8(11.4)$ & $61(16.8)$ & $<0.001$ \\
\hline i. & Pneumonia & $32(25.2)$ & $11(12.2)$ & $10(13.2)$ & $8(11.4)$ & $61(16.8)$ & \\
\hline 4. & Eye diseases & $10(7.9)$ & $14(15.6)$ & $10(13.2)$ & $15(21.4)$ & 49 (13.5) & 0.638 \\
\hline i. & Conjunctivitis & $2(1.6)$ & $7(7.8)$ & $1(1.3)$ & $3(4.3)$ & $13(3.6)$ & \\
\hline ii. & Corneal opacity & $8(6.3)$ & $7(7.8)$ & $9(11.8)$ & $12(17.1)$ & $36(9.9)$ & \\
\hline 5. & Musculo-skeletal disorder & $6(4.7)$ & $2(2.2)$ & $1(1.3)$ & $3(4.3)$ & $12(3.3)$ & 0.198 \\
\hline i. & Arthritis & $6(4.7)$ & $2(2.2)$ & $1(1.3)$ & $3(4.3)$ & $12(3.3)$ & \\
\hline 6. & Skin conditions & $1(0.8)$ & $1(1.1)$ & $\mathbf{0}$ & $1(1.4)$ & $3(0.8)$ & 1.000 \\
\hline i. & Dermatitis & $1(0.8)$ & $1(1.1)$ & 0 & 0 & $2(0.6)$ & \\
\hline ii. & Bee sting & 0 & 0 & 0 & $1(1.4)$ & $1(0.3)$ & \\
\hline 7. & Parasitic diseases & $25(19.7)$ & $29(32.2)$ & $11(14.5)$ & $9(12.9)$ & $74(20.4)$ & 0.001 \\
\hline i. & Helminth infection & $21(16.5)$ & $22(24.4)$ & $9(11.8)$ & $6(8.6)$ & $58(15.9)$ & \\
\hline ii. & Ectoparasitic infestation & $1(0.8)$ & $7(7.8)$ & 0 & $1(1.4)$ & $9(2.5)$ & \\
\hline iii. & Babesiosis & $1(0.8)$ & 0 & $1(1.3)$ & 0 & $2(0.6)$ & \\
\hline iv. & Coccidiosis & $2(1.6)$ & 0 & $1(1.3)$ & $2(2.9)$ & $5(1.4)$ & \\
\hline 8. & Infectious diseases & $11(8.7)$ & $10(11.1)$ & $13(17.1)$ & 9 (12.9) & $43(11.8)$ & 0.846 \\
\hline i. & Tetanus & 0 & $2(2.2)$ & $1(1.3)$ & $1(1.4)$ & $4(1.1)$ & \\
\hline ii. & PPR & $8(6.3)$ & 0 & $8(10.5)$ & $3(4.3)$ & $19(5.2)$ & \\
\hline iii. & Foot rot & 0 & $1(1.1)$ & $2(2.6)$ & $2(2.9)$ & $5(1.4)$ & \\
\hline iv. & Dog bite & $3(2.4)$ & $7(7.8)$ & $2(2.6)$ & $3(4.3)$ & $15(4.1)$ & \\
\hline 9. & $\begin{array}{l}\text { Nutritional deficiency } \\
\text { disease }\end{array}$ & $1(0.8)$ & $1(1.1)$ & $\mathbf{0}$ & $1(1.4)$ & $3(0.8)$ & 1.000 \\
\hline i. & Vitamin B1 deficiency & $1(0.8)$ & $1(1.1)$ & 0 & $1(1.4)$ & $3(0.8)$ & \\
\hline Sub-total & I (medicinal cases) & $127(81.9)$ & $90(71.4)$ & $76(82.6)$ & $70(82.4)$ & $363(81.0)$ & $<0.001$ \\
\hline 1. & Repeat beeding & 0 & $1(50.0)$ & 0 & 0 & $1(20.0)$ & \\
\hline 2. & Metritis & $1(100.0)$ & 0 & $1(50.0)$ & 0 & $2(40.0)$ & \\
\hline 3. & Uterine prolapsed & 0 & $1(50.0)$ & 0 & 0 & $1(20.0)$ & \\
\hline 4. & Dystocia & 0 & 0 & $1(50.0)$ & 0 & $1(20.0)$ & \\
\hline $\begin{array}{l}\text { Sub-total } \\
\text { cases) }\end{array}$ & (Gynaeco-obstetrical & $1(0.6)$ & $2(1.7)$ & $2(2.2)$ & $\mathbf{0}$ & $5(1.1)$ & 0.819 \\
\hline 1. & Abscess & $1(3.7)$ & 0 & 0 & 0 & $1(1.3)$ & \\
\hline 2. & Traumatic wound & $6(22.2)$ & $6(25.0)$ & $6(42.9)$ & $5(33.3)$ & $23(28.8)$ & \\
\hline 3. & Castration & $14(51.9)$ & $7(29.2)$ & $1(7.1)$ & $3(20.0)$ & $25(31.3)$ & \\
\hline 4. & Myiasis & $3(11.1)$ & 0 & $4(28.6)$ & $5(33.3)$ & $12(15.0)$ & \\
\hline 5. & Nasal polyps & 0 & $1(4.2)$ & 0 & 0 & $1(1.3)$ & \\
\hline 6. & Fracture & 0 & $6(29.2)$ & $2(14.3)$ & $1(6.7)$ & $9(11.3)$ & \\
\hline 7. & Gid disease & $1(3.7)$ & $1(4.2)$ & 0 & 0 & $2(2.5)$ & \\
\hline & Congenital defects & $2(7.4)$ & $3(12.5)$ & $1(7.1)$ & $1(6.7)$ & $7(8.8)$ & \\
\hline Sub-total & I (Surgical cases) & $27(17.4)$ & $24(20.7)$ & $14(15.2)$ & $15(17.6)$ & $80(17.9)$ & 0.098 \\
\hline Overall & & 155 & 116 & 92 & 85 & 448 & $<0.001$ \\
\hline
\end{tabular}


Table 4. Season-wise distribution of clinical cases of goats recorded at the PSTU Veterinary Clinic during four years' period from 2008 to 2011

\begin{tabular}{|c|c|c|c|c|c|c|}
\hline \multirow[t]{2}{*}{ Sl. No. } & \multirow[t]{2}{*}{ Diseases (Goat) } & \multicolumn{3}{|c|}{ No. $(\%)$ of cases } & \multirow[t]{2}{*}{ Overall } & \multirow[t]{2}{*}{ P-value } \\
\hline & & Winter & Summer & Rainy & & \\
\hline 1. & Systemic states & $11(10.3)$ & $11(8.6)$ & $13(10.2)$ & $35(9.6)$ & 0.892 \\
\hline i. & Fever & $4(3.7)$ & $4(3.1)$ & $8(6.3)$ & $16(4.4)$ & \\
\hline ii. & Malnutrition & $6(5.6)$ & $7(5.5)$ & $5(3.9)$ & $18(4.9)$ & \\
\hline iii. & Food poisoning & $1(0.9)$ & 0 & 0 & $1(0.3)$ & \\
\hline 2. & Digestive disorders & $30(28.0)$ & $26(20.3)$ & $27(21.1)$ & $83(22.9)$ & 0.855 \\
\hline i. & Bloat & $3(2.8)$ & $1(0.8)$ & $5(3.9)$ & $9(2.5)$ & \\
\hline ii. & Simple Indigestion & 0 & $1(0.8)$ & $2(1.6)$ & $3(0.8)$ & \\
\hline iii. & Enteritis & $7(6.5)$ & $11(8.6)$ & $4(3.1)$ & $22(6.1)$ & \\
\hline iv. & Diarrhoea & $18(16.8)$ & $12(9.4)$ & $14(10.9)$ & $44(12.1)$ & \\
\hline v. & Abdominal pain & $1(0.9)$ & $1(0.8)$ & 0 & $2(0.6)$ & \\
\hline vi. & Stomatitis & $1(0.9)$ & 0 & $2(1.6)$ & $3(0.8)$ & \\
\hline 3. & Respiratory disorder & $14(13.1)$ & $26(20.3)$ & $21(16.4)$ & $61(16.8)$ & 0.167 \\
\hline i. & Pneumonia & $14(13.1)$ & $26(20.3)$ & $21(16.4)$ & $61(16.8)$ & \\
\hline 4. & Eye diseases & $9(8.4)$ & $12(9.4)$ & $28(21.9)$ & $49(13.5)$ & 0.002 \\
\hline i. & Conjunctivitis & $2(1.9)$ & $5(3.9)$ & $6(4.7)$ & $13(3.6)$ & \\
\hline ii. & Corneal opacity & $7(6.5)$ & $7(5.5)$ & $22(17.2)$ & $36(9.9)$ & \\
\hline 5. & Musculo-skeletal disorder & 2 (1.9) & $7(5.5)$ & $3(2.3)$ & $12(3.3)$ & 0.174 \\
\hline i. & Arthritis & $2(1.9)$ & $7(5.5)$ & $3(2.3)$ & $12(3.3)$ & \\
\hline 6. & Skin conditions & $1(0.9)$ & $1(0.8)$ & $1(0.8)$ & $3(0.8)$ & 1.000 \\
\hline i. & Dermatitis & 0 & $1(0.8)$ & $1(0.8)$ & $2(0.6)$ & \\
\hline ii. & Bee sting & $1(0.9)$ & 0 & 0 & $1(0.3)$ & \\
\hline 7. & Parasitic diseases & $25(23.4)$ & $21(16.4)$ & $28(21.9)$ & $74(20.4)$ & 0.607 \\
\hline i. & Helminth infection & $18(16.8)$ & $15(11.7)$ & $25(19.5)$ & $58(15.9)$ & \\
\hline ii. & Ectoparasitic infestation & $3(2.8)$ & $3(2.3)$ & $3(2.3)$ & $9(2.5)$ & \\
\hline iii. & Babesiosis & 0 & $2(1.6)$ & 0 & $2(0.6)$ & \\
\hline iv. & Coccidiosis & $4(3.7)$ & $1(0.8)$ & 0 & $5(1.4)$ & \\
\hline 8. & Infectious diseases & $14(13.1)$ & $23(17.9)$ & $6(4.7)$ & $43(11.8)$ & 0.006 \\
\hline i. & Tetanus & $1(0.9)$ & $3(2.3)$ & 0 & $4(1.1)$ & \\
\hline ii. & PPR & $5(4.7)$ & $11(8.9)$ & $3(2.3)$ & $19(5.2)$ & \\
\hline iii. & Foot rot & $2(1.9)$ & $3(2.3)$ & 0 & $5(1.4)$ & \\
\hline iv. & Rabies & $6(5.6)$ & $6(4.7)$ & $3(2.3)$ & $15(4.1)$ & \\
\hline 9. & Nutritional deficiency disease & $1(0.9)$ & $1(0.8)$ & $1(0.8)$ & $3(0.8)$ & 1.000 \\
\hline i. & Vitamin B1 deficiency & $1(0.9)$ & $1(0.8)$ & $1(0.8)$ & $3(0.8)$ & \\
\hline \multicolumn{2}{|c|}{ Sub-total (medicinal cases) } & 107(87.7) & $128(70.3)$ & $128(88.9)$ & $363(81.0)$ & 0.297 \\
\hline 1. & Repeat beeding & 0 & $1(25.0)$ & 0 & $1(20.0)$ & \\
\hline 2. & Metritis & $1(100.0)$ & $1(25.0)$ & 0 & $2(40.0)$ & \\
\hline 3. & Uterine prolapsed & 0 & $1(25.0)$ & 0 & $1(20.0)$ & \\
\hline 4. & Dystocia & 0 & $1(25.0)$ & 0 & $1(20.0)$ & \\
\hline \multicolumn{2}{|c|}{ Sub-total (Gynaeco-obstetrical cases) } & $1(0.8)$ & $4(8.9)$ & $\mathbf{0}$ & $5(1.1)$ & 0.180 \\
\hline 1. & Abscess & 0 & $1(3.0)$ & 0 & $1(1.3)$ & \\
\hline 2. & Traumatic wound & $6(42.9)$ & $10(20.0)$ & $7(43.8)$ & $23(28.8)$ & \\
\hline 3. & Castration & $4(28.6)$ & $14(28.0)$ & $7(43.8)$ & $25(31.3)$ & \\
\hline 4. & Myiasis & $1(7.1)$ & $11(22.0)$ & 0 & $12(15.0)$ & \\
\hline 5. & Nasal polyps & $1(7.1)$ & 0 & 0 & $1(1.3)$ & \\
\hline 6. & Fracture & $1(7.1)$ & $7(14.0)$ & $1(6.3)$ & $9(11.3)$ & \\
\hline 7. & Gid disease & 0 & $2(4.0)$ & 0 & $2(2.5)$ & \\
\hline 8. & Congenital defects & $1(7.1)$ & $5(10.0)$ & $1(6.3)$ & $7(8.8)$ & \\
\hline \multicolumn{2}{|c|}{ Sub-total (Surgical cases) } & 14(11.5) & $50(27.5)$ & $16(11.1)$ & $80(17.9)$ & $<0.001$ \\
\hline \multicolumn{2}{|c|}{ Overall } & 122 & 182 & 144 & 448 & 0.002 \\
\hline
\end{tabular}




\section{A. Rahman and others}

\section{Nasal polyps}

This study recorded $1.1 \%$ and $1.3 \%$ nasal polyps in cattle and goats, respectively (Table 1 and 3 ). However, the recorded nasal polyps in ruminants could not be compared due to lack of similar inland reports. Nasal polyps were recorded only in summer season $(1.6 \%)$ but in case of goats, the case was recorded only in winter season (7.1\%) (Table 2 and 4$)$.

\section{Urolithiasis}

Urolithiasis was recorded only in $1.1 \%$ cattle (Table 1$)$. Samad (2001) reported very low percentage $(0.02 \%)$ of obstructive urolithiasis in cattle. Urolithiasis was recorded only in winter season (7.7\%) (Table 2).

\section{Dehorning}

Only $4(4.5 \%)$ cattle were brought for treatment with broken or overgrown horn during this four years' study period (Table 1). Hossain et al. (1986) reported 0.9\% dehorning cases in cattle and Samad (2001) reported $0.65 \%$ and $0.08 \%$ dehorning cases in cattle and goats, respectively.

\section{Navel-ill}

Navel-ill was recorded only in $10.1 \%$ cattle (Table 1). This observation supports the report of Das and Hashim (1996) who reported 6.40\% navel-ill in calves. However, Samad (2001) recorded $0.79 \%$ and $0.62 \%$ navel-ill cases in calves and kids, respectively. The highest cases were recorded during winter (15.4\%) and summer $(11.3 \%)$ seasons (Table 2$)$.

\section{Upward patellar fixation}

This case was recorded only in $2(2.2 \%)$ cattle (Table 1$)$. Cases were recorded only in summer season (3.2\%) (Table 2). However, the recorded cases in cattle could not be compared due to lack of similar inland reports.

\section{Fracture}

Fracture was recorded in 11.3\% goats (Table 3). Hossain et al. (1986) and Samad (2001) recorded 8.2\% and $1.1 \%$ fracture cases among surgical conditions in goats.

\section{Gid disease}

Gid disease was recorded only in two goats (2.5\%) (Table 3). Samad (2001) recorded 5.38\% gid disease in goats. The occurrence of gid disease was found only in summer season $(4.0 \%)$ (Table 4$)$.

\section{Congenital defects}

This study recorded a total of 7 goats (1.9\%) with congenital defects at PSTU Veterinary Clinic during four years' period (Table 3). Comparatively higher percentage of cases was recorded during summer (3.8\%) than winter $(0.9 \%)$ and rainy $(0.8 \%)$ seasons (Table 4$)$. This observation partially supports the findings of Samad (2001) who reported higher number of congenital defects in calves during summer (38.89\%) and rainy (38.89\%) seasons than winter $(22.22 \%)$ season.

The knowledge derived from this study will increase clinicians' understanding about the clinical cases of cattle and goats in a particular area and subsequently will help to take necessary preventive measures of the diseases.

\section{REFERENCES}

1. Ali ML, Nooruddin M and Debnath NC (1997). Retrospective study of periparturient diseases in dairy cows. 2. Metritis complex. Bangladesh Veterinarian 14: 48-52.

2. Das BC and Hashim MA (1996). Studies on surgical affections in calves. Bangladesh Veterinary Journal 30: 53-57. 
3. Debnath NC, Sil BK, Selim SA, Prodhan MAM and Howlader MMR (1990). A retrospective study of calf mortality and morbidity on smallholder traditional farms in Bangladesh. Preventive Veterinary Medicine 9: $1-7$.

4. Hoque MS and Samad MA (1996). Prevalence of clinical diseases in dairy cross-bred cows and calves in the urban areas in Dhaka. Bangladesh Veterinary Journal 30: 118-129.

5. Hoque MS and Samad MA (1997). Present status of clinical diseases of goats in the urban areas in Dhaka. Bangladesh Veterinary Journal 31: 35-40.

6. Hossain MA, Shaidullah M and Ali MA (1986). A report on surgical diseases and reproductive disorders recorded at the Veterinary Hospital of Bangladesh Agricultural University, Mymensingh. Bangladesh Veterinary Journal 20: 1-5.

7. Islam MS, Howlader MMR, Hossain MA, Rahman MF and Jahan S (1998). Status of reproductive disorders in cows at the six artificial insemination pocket areas in Bangladesh. Bangladesh Veterinary Journal 32: $152-153$.

8. Kabir MH, Reza MA, Razi KMA, Parvez MM, Bag MAS and Mahfuz SU (2010). A report on clinical prevalence of diseases and disorders in cattle and goat at the Upazilla Veterinary Hospital, Ulipur, Kurigram. Internatioal Journal of BioResearch 2: 17-23.

9. Nooruddin M, Sarker AJ, Baki MA, Ali MR, Dey AS and Hoque MF (1986). Prevalence of diseases of external organs of cattle. Bangladesh Veterinary Journal 20: 11-16.

10. Pallab MS, Ullah SM, Uddin MM and Miazi OF (2012). A cross sectional study of several diseases in cattle at Chandanaish Upazilla of Chittagong district, Bangladesh. Scientific Journal of Veterinary Advances 1: 28-32.

11. Pharo HJ (1987). Analysis of clinical case records from dairy co-operatives in Bangladesh. Tropical Animal Health and Production 19: 136-142.

12. Rahman A, Ahmed JU and Haque MA (1975). Analysis of lameness of cattle admitted to the Veterinary Hospital of Bangladesh Agricultural University. Bangladesh Veterinary Journal 9: 21-24.

13. Rahman MA, Ali KM and Rahman A (1972). Incidence of diseases of cattle in Mymensingh. Bangladesh Veterinary Journal 6: 25-30.

14. Rahman MM, Ali M and Hashem A (1999). Livestock disease problems in a selected area of Sherpur district. Bangladesh Journal of Train Dev 12: 205-210.

15. Samad MA (2001). Observations of clinical diseases in ruminants at the Bangladesh Agricultural University Veterinary Clinic. Bangladesh Veterinary Journal 35: 93-120.

16. Samad MA, Islam MA and Hossain A (2002). Patterns of occurrence of calf diseases in the district of Mymensingh in Bangladesh. Bangladesh Veterinary Journal 36: 01-05.

17. Sarker MAS, Hashim MA, Rahman MB and Begum H (1999). Studies on bovine lymphadenitis syndrome. Bangladesh Veterinarian 10: 6-8.

18. Shahadat A, Karim MJ, Alam MZ and Majumder S (2003). Seasonal distribution of Haemonchus contortus in Bengal goats. Bangladesh Veterinarian 20: 72-76. 